\title{
A criação das fazendas-modelo em Minas Gerais: uma política pública para a educação profissional agrícola na Primeira República (1906-1914) ${ }^{1}$
}

\section{The establishment of model-farms in Minas Gerais: a public policy for agricultural professional education during the First Republic (1906-1914)}

\author{
Daniela Pereira Versieux* \\ Irlen Antônio Gonçalves**
}

\begin{abstract}
Resumo
Este artigo objetiva compreender a política de fundação de fazendas-modelo em Minas Gerais, entre 1906 e 1908, geradora de proposições de instituições voltadas à formação do trabalhador do campo e, sobretudo, para o campo. Objetiva também captar alguns indícios da materialidade das fazendas-modelo que existiram no período. Para tal, optamos por cruzar e problematizar as seguintes fontes primárias: legislação estadual; anais do Congresso Legislativo Mineiro; textos de João Pinheiro da Silva (mensagens presidenciais, cartas recebidas e expedidas e textos publicados no jornal Minas Gerais); relatórios da Diretoria de Agricultura do Estado de Minas Gerais. Pode-se considerar que as fazendas-modelo existiram enquanto instituições de ensino agrícola prático, voltadas para um público adulto e trabalhador e se inseriram em um processo mais amplo de modernização da agricultura mineira.
\end{abstract}

Palavras-chave: Fazendas-modelo. História do ensino agrícola. Política pública.

\footnotetext{
${ }^{1}$ Este texto é resultado das pesquisas que os autores vêm desenvolvendo nos últimos anos, no Centro Federal de Educação Tecnológica de Minas Gerais - CEFET-MG. Faz parte de um programa de pesquisa, coordenado por Irlen Antônio Gonçalves, intitulado A ESCOLARIZAÇÃO DO TRABALHADOR MINEIRO: as políticas públicas para a educação profissional, contando com o apoio financeiro do CNPq e da FAPEMIG; e da Dissertação de Mestrado de Daniela Pereira Versieux, defendida no Programa de Pós-Graduação em Educação Tecnológica, do CEFET-MG, apoiada pela Fundação de Ensino de Contagem.

* Mestre em Educação Tecnológica pelo Centro Federal de Educação Tecnológica de Minas Gerais. Professora do Instituto Federal de Educação, Ciência e Tecnologia de Goiás (campus Formosa). E-mail: danielaversieux@yahoo.com.br

** Doutor em Educação pela Universidade Federal de Minas Gerais. Professor-orientador do programa de Pós-Graduação em Educação Tecnológica do Centro Federal de Educação Tecnológica de Minas Gerais.
} 


\begin{abstract}
This paper aims to understand how the model farms's policy in Minas Gerais (Brazil) was prepared by the intellectuality during the administration of the President of State João Pinheiro da Silva (1906-1908). It also aims to capture some evidence of the materiality of model farms that existed in the period. To this end, we chose to cross and question primary sources: state legislation; annals of Congresso Legislativo de Minas Gerais; texts of João Pinheiro da Silva (presidential messages, letters received and dispatched, papers published in the official newspaper Minas Gerais); reports office of Agriculture of the State of Minas Gerais.
\end{abstract}

Keywords: Model-farms. Agricultural schooling history. Public policy.

No Brasil, a preocupação em formar trabalhadores para o campo em seu locus produtivo - a fazenda - remonta ao século XIX. ${ }^{2}$ Em que pese a ausência de pesquisas sobre o ensino agrícola no século XIX, particularmente no período imperial, essa lacuna foi detectada também na historiografia referente ao período conhecido como Primeira República. ${ }^{3}$ Interessa-nos, pois, problematizar as questões relacionadas à implantação das políticas públicas para a educação profissional em Minas Gerais, nas primeiras décadas republicanas, tendo o foco principal a criação das fazendas-modelo, instituições de ensino agrícola surgidas no Estado a partir de 1906 e extintas, em sua maioria, em meados da segunda década do século XX.

2 Para o aprofundamento dos estudos sobre o a educação rural no Brasil, sugerimos a leitura de MENDONÇA, Sonia Regina de. Estado e educação rural no Brasil: alguns escritos. Rio de Janeiro: Vício de Leitura/ FAPERJ, 2007. Sobre a institucionalização das ciências agrárias, a tese de OLIVER, Graciela de Souza. 0 papel das Escolas Superiores de Agricultura na institucionalização das ciências agrícolas no Brasil, 1930-1950: práticas acadêmicas, currículos e formação profissional. 2005. 326f. (Tese de Doutorado, Ensino e História de Ciências da Terra). Instituto de Geociências, UNICAMP, Campinas, 2005, p. 31. Sobre as questões agrárias nos Estados, ver estudos de: Bruno Capilé (2010) e Maria Fernanda Vieira Martins (1995), que estudaram tais questões no Rio de Janeiro; CAPILÉ, Bruno. A mais santa das causas: a Revista Agrícola do Imperial Instituto Fluminense de Agricultura (1869-1891). Dissertação de Mestrado. Rio de Janeiro: Universidade Federal do Rio de Janeiro, 2010; MARTINS, Maria Fernanda Vieira. O Imperial Instituto Fluminense de Agricultura: Elites, Política e Reforma Agrícola. Dissertação de Mestrado. Niterói: UFF, 1995. Mário Roberto Ferraro (2005), que estudou a Gênese da agricultura no Estado de São Paulo. FERRARO, Mário Roberto. A gênese da agricultura e da silvicultura moderna no Estado de São Paulo. Dissertação de Mestrado. Piracicaba: ESALQ/USP, 2005. Sobre a agronomia na Bahia, os estudos de Nilton de Almeida Araújo (2010). ARAÚJO, Nilton de Almeida. Pioneirismo e Hegemonia: a Construção da Agronomia como Campo Científico na Bahia (1832-1911). Tese de Doutorado. Niterói: UFF, 2010.

${ }^{3}$ Ver Dissertação de Mestrado de Daniela Pereira Versieux (2010) e Tese de Doutorado de Marli de Souza Saraiva Cimino (2013). VERSIEUX, Daniela Pereira. Modernização e escolarização do trabalho agrícola: as fazendas-modelo em Minas Gerais (1906-1915). 2010. 232f. Centro Federal de Educação Tecnológica de Minas Gerais: Belo Horizonte, 2010; CIMINO, Marli de Souza Saraiva. Iluminar a terra pela inteligência: trajetória do Aprendizado Agrícola de Barbacena, MG (1910-1933). Universidade do Estado do Rio de Janeiro: Rio de Janeiro, 2013. 
Nosso intuito é, pois, compreender como a política de fundação de fazendas-modelo foi tecida por parte das elites no poder e como foi geradora de proposições de instituições voltadas para a formação do trabalhador do/ para o campo. Objetivamos também captar alguns indícios da materialidade das fazendas-modelo.

Para atingirmos os objetivos propostos, procuramos cruzar e problematizar as seguintes fontes primárias: a legislação estadual referente ao ensino agrícola publicada entre 1906 e 1914; os Anais do Congresso Legislativo Mineiro, referentes aos anos de 1894 e 1906; os escritos do presidente de Minas Gerais João Pinheiro - mensagens presidenciais, cartas recebidas e enviadas e textos divulgados na imprensa durante o seu segundo mandato como chefe do executivo (1906 a 1908) - nos quais ele explicita proposições de governo relativas às fazendas-modelo; os relatórios e expedientes publicados entre 1907 e 1915 pela Diretoria de Agricultura. ${ }^{4}$

A instalação das fazendas-modelo teve início com a promulgação da lei n. 438, em 24 de setembro de 1906, que tratava de pôr em prática parte do programa de governo de João Pinheiro da Silva. Esta lei autorizava o executivo a fundar seis fazendas-modelo agrícola-pastoris, às expensas do Estado, além de autorizar a criação de seis colônias agrícolas, um laboratório de análises de terras e o estudo de poços artesianos.

No que se refere às fazendas-modelo, a lei 438/1906 indicou que estas ministrassem o ensino técnico profissional secundário, "o mais prático possível", bem como permitiu que o governo auxiliasse as Câmaras Municipais e particulares que fundassem estabelecimentos desse tipo. Definiu ainda que as fazendas-modelo teriam como finalidade a "sistematização das culturas existentes por processos aperfeiçoados e para aclimação e seleção, de boas raças de animais". ${ }^{5}$

A lei 438/1906 iniciou a sua tramitação na Câmara dos Deputados, no Congresso Legislativo Mineiro, em 14 de agosto de 1906, por intermédio do deputado Bernardino de Sena Figueiredo. Ao propor o projeto de número 167, Sena Figueiredo explicitou a articulação entre ensino profissional agrícola, povoamento do solo (ou colonização por imigrantes) e modificação

\footnotetext{
${ }^{4}$ A Diretoria de Agricultura era o órgão estadual responsável, em Minas Gerais, pelos assuntos da Agricultura, Comércio, Terras e Colonização, que esteve vinculado à Secretaria das Finanças até 1910, quando foi recriada a Secretaria de Agricultura, Indústria, Terras, Viação e Obras Públicas. Esta Diretoria foi incumbida de instalar, fiscalizar e administrar as fazendas-modelo no período aqui estudado (VERSIEUX, op. cit., 2010).

${ }^{5}$ MINAS GERAIS. Coleção de Leis e Decretos do Estado de Minas Gerais: 1906. Belo Horizonte, Imprensa Oficial do Estado de Minas Gerais, 1906, p. 19.
} 
de costumes agrícolas com o desenvolvimento econômico do Estado. E, ao fazê-lo, considerou que o seu projeto era a "chave da relação do problema econômico do Estado". ${ }^{6}$ Em outras palavras, compreender - e solucionar - o problema econômico nas Minas Gerais do início do século XX passava necessariamente por superar a "falta de braços, a falta de preparo técnico do lavrador e o povoamento das grandes propriedades". ${ }^{7}$

Essa fórmula já vinha sendo defendida pelo menos desde o início da República. As tentativas de se disseminar o ensino agrícola em Minas Gerais, por meio do estabelecimento de instituições de ensino agrícola, professores ambulantes e revistas de divulgação de métodos mecânicos de agricultura estavam vinculadas à política de colonização do solo mineiro, por meio da entrada e fixação de imigrantes no Estado e à introdução de novos métodos, processos e hábitos na agricultura, com vistas a superar o então chamado "método rotineiro". ${ }^{8}$ Diferentemente do início da República, porém, em 1906 essa ideia estava mais bem acabada, concisa e articulada. Em relação ao povoamento do solo, por exemplo, Sena Figueiredo entendia que

o parcelamento dos grandes latifúndios dos Estados Unidos, e em grande parte da Argentina e da Bélgica, foi causa eficiente do desenvolvimento da produção, a ponto do resultado colhido do trigo, milho, linho e alfafa na Argentina causar espanto ao mundo inteiro, seduzindo a imigração para aqueles países. ${ }^{9}$

Esse parlamentar fazia uma defesa vigorosa da divisão das grandes propriedades. Talvez uma reforma agrária às avessas, de cima para baixo, com a intervenção indireta do poder público, sensibilizando os grandes proprietários para a questão. Sena Figueiredo defendia que "o fazendeiro, vendo o resultado da colonização promovida pelo Estado", facilmente entregaria as suas terras aos "colonos, promovendo-lhes os meios". ${ }^{10}$ Além do mais, o deputado percebia a imigração como intrinsecamente vinculada ao ensino agrícola. Para ele, seria o colono imigrante que daria o exemplo ao lavrador brasileiro do amor ao trabalho, da valorização da terra, da lida agrícola. 0 estrangeiro daria o exemplo ao brasileiro que se queria disciplinar para o

\footnotetext{
${ }^{6}$ CONGRESSO MINEIRO. Anais da Câmara dos Deputados: quarta sessão da quarta legislatura - 1906. Belo Horizonte: Imprensa Oficial do Estado de Minas Gerais, 1906, p. 307.

${ }^{7}$ Ibidem, p. 307.

${ }^{8}$ CONGRESSO MINEIRO. Anais da Câmara dos Deputados: 1894. Ouro Preto: Imprensa Oficial do Estado de Minas Gerais, 1894.

${ }^{9}$ CONGRESSO MINEIRO, op. cit., 1906, p. 308.

${ }^{10}$ Ibidem, p. 414.
} 
trabalho pela "dedicação à cultura, [...] pela economia, pelo método e aproveitamento do tempo e das coisas mais insignificantes, a que o nacional não liga a mínima importância". ${ }^{11} \mathrm{O}$ ensino agrícola, estreitamente vinculado à colonização, serviria, então, para impulsionar a adoção dos novos processos agrícolas.

$\mathrm{Na}$ visão de Sena Figueiredo as fazendas-modelo, ou campos de demonstração, seriam os estabelecimentos que proporcionariam esse sistema de imitação, o locus no qual o trabalhador agrícola e pastoril veria os novos métodos e processos de cultura serem empregados, facultando aos mesmos

o ensino prático, o modo de conhecer o meio de cultivar essa ou aquela planta, de acordo com a qualidade do terreno que possui e por processos que compensem os esforços empregados, e ainda aplicação prática de máquinas, começando pelas mais simples. ${ }^{12}$

Em fins do século XIX, o ensino agrícola era pensado em termos de institutos agronômicos e zootécnicos, escolas fazendas, estações agronômicas e campos de demonstração, fundamentalmente por meio de cursos teórico-práticos. Para tais cursos previa-se: o estabelecimento de cadeiras de diversas disciplinas; o concurso de professores estrangeiros, por se considerar não existirem no país profissionais do tipo requerido; edifícios e diversas outras instalações, sendo a fazenda agrícola e pastoril uma parte do estabelecimento. A partir das proposições construídas pelo executivo e legislativo mineiros da primeira década do século XX, as fazendas passaram a constituir a própria instituição de ensino agrícola, assumindo a forma de campos de demonstração e de fazendas-modelo, às quais vão se juntar um pouco mais tarde os institutos primário-agrícolas. ${ }^{13} \mathrm{~A}$ fazenda passou a ocupar lugar central no processo de ensino-aprendizagem dos processos agrícolas, tornado meramente prático, formando mestres de cultura, ensinando o manejo de máquinas agrícolas aos "operários agrícolas"14 e convencendo os fazendeiros e lavradores, pelo exemplo, a adotarem os processos modernos de cultura.

\footnotetext{
${ }^{11}$ Ibidem, p. 310.

${ }^{12}$ Ibidem, p. 309.

${ }^{13} \mathrm{Em} 9$ de fevereiro de 1909, pelo decreto 2.416 foi criado o Instituto João Pinheiro, na Fazenda-modelo da Gameleira. Nesse mesmo ano, o decreto n. 2.826, de 14 de maio, criou o Instituto Dom Bosco, que foi instalado somente em 30 de maio de 1910, em Itajubá. E, em 1ํ de agosto de 1911 o decreto 3.261 instituiu o Instituto Bueno Brandão, situado no município de Mar de Espanha.

${ }^{14}$ Os operários agrícolas eram os trabalhadores do campo, também chamados de jornaleiros, pois recebiam seus salários em forma de "jornal”, ou diárias.
} 
Secundarizando o ensino teórico, essas instituições estariam voltadas para a produção: era primordial para o sucesso da política de ensino agrícola de João Pinheiro que as fazendas-modelo produzissem. E não apenas produzissem, mas que o fizessem em maior quantidade, melhor qualidade e com custos menores em relação aos métodos extensivos, ditos rotineiros. Por ter defendido de forma assertiva e sistemática esse caráter produtivo das fazendas-modelo, objeto do estudo aqui relatado, utilizaremos alguns textos escritos por ou atribuídos a João Pinheiro.

Alguns textos publicados no jornal Minas Gerais entre 1906 e 1908 têm sua autoria atribuída ao então presidente do Estado. Um dos compiladores mais reconhecidos dos escritos de João Pinheiro, Francisco de Assis Barbosa, ao elaborar uma "cronologia" de sua vida cita en passant uma série de artigos publicados no Minas Gerais entre 25 de novembro de 1906 e 09 de junho de $1907^{15}$, sob a forma de editoriais. Estes artigos versavam principalmente sobre

o programa e os propósitos do Governo de João Pinheiro, no sentido de melhor assistir aos agricultores, com a introdução de máquinas modernas e novos processos de trabalho, além da instalação de fazendas-modelo". Apesar de não terem sido assinados, "a autoria desses artigos tem sido atribuída ao próprio João Pinheiro. ${ }^{16}$

Consideramos pertinente esta atribuição da autoria a João Pinheiro por dois motivos. Primeiro, ao contrapor o conteúdo e forma desses editoriais a algumas cartas do então presidente do Estado endereçadas a Afonso Pena, na época presidente do país, que estão sob a guarda do Arquivo Nacional do Rio de Janeiro e depositadas no Fundo Afonso Pena, encontramos semelhanças entre as informações contidas em uns e outros. Mais adiante, ao retomar as questões sobre as fazendas-modelo, citamos uma passagem de um dos editoriais e de uma das cartas, que servirá para exemplificar as semelhanças com as quais nos deparamos.

O segundo motivo reside no conteúdo de uma carta escrita por Afrânio de Melo Franco e dirigida a João Pinheiro. Na missiva, Melo Franco afirmou

\footnotetext{
${ }^{15}$ Os artigos a que se referiu Barbosa (1980) foram publicados nas edições do jornal Minas Gerais dos dias 2/11/1906, 7/02, 10/02, 21/3, 12/05, 19/05 e 09/06 de 1907. É possível incluir nessa série outro editorial publicado em 12/08/1908 sob o título "A cultura dos cereais".

${ }^{16}$ BARBOSA, Francisco de Assis. "Cronologia”. In: BARBOSA, Francisco de Assis. As Ideias Políticas de João Pinheiro: cronologia, introdução, notas bibliográficas e textos selecionados. Brasília: Senado Federal/MEC; Rio de Janeiro: Fundação Rui Barbosa, 1980, p. 26.
} 
ter "lido neste momento o seu artigo, publicado no Minas de ontem, sobre a fazenda da Gameleira". ${ }^{17}$ Data e assunto coincidem com um dos editoriais citados por Barbosa na sua "cronologia". ${ }^{18}$ A discussão sobre a atribuição da autoria dos editoriais a João Pinheiro encetada por Barbosa (1980) é aqui aprofundada a fim de assinalar o comprometimento da política de governo de João Pinheiro com produção agrícola:

na primeira fazenda-modelo, tipo n. 1, que está sendo instalada nas proximidades desta Capital, começará amanhã o serviço de roçada, que vai preceder ao do desbravamento do solo.

[...]

Com o intuito de ser uma lição permanente, podendo ser acompanhada com interesse por todos que estão longe e queiram aprender a grande utilidade dos orçamentos especificados - publicaremos periodicamente a despesa feita e o serviço obtido. Nesta publicação se especificará o custo das roçadas por unidade de serviço, o custo do trabalho da terra pelos arados, também por unidade de serviço, a natureza dos arados empregados, número de trabalhadores lidando com os mesmos, número de bois ou muares empregados, numa palavra, toda a despesa feita por quinzena e todo o serviço obtido nesta mesma quinzena. ${ }^{19}$

Em carta a Afonso Pena, então presidente do país, João Pinheiro afirmou que ele próprio conduzia os trabalhos de cultura agrícola na primeira fazenda-modelo fundada por ele, a fazenda da Gameleira. Dessa forma, escreveu a Afonso Pena:

especifiquei por unidade de serviço, acostumando este trabalhador a pequenas empreitadas, o custo das cercas de arame farpado por metro, o custo da remoção da terra para os regos de irrigação, o custo da destocação por hectare, o custo da lâmina do arado, do destocador e da gradagem. ${ }^{20}$

Pode-se inferir que a produção agrícola e pastoril foi a forma concreta pela qual a aprendizagem profissional ocorreu nas fazendas-modelo. Tal aprendizagem deu-se de forma essencialmente prática e esteve vinculada

\footnotetext{
${ }^{17}$ FRANCO, Afrânio de Melo. 1907. Carta a João pinheiro, de 13/05/1907. In: ARQUIVO PRIVADO DE JOÃO PINHEIRO DA SILVA. Série II - Correspondências. Carta n. 2550. Arquivo Público Mineiro, Belo Horizonte, Minas Gerais, 1907.

${ }^{18}$ BARBOSA, op. cit., 1980.

${ }^{19}$ AGRICULTURA. Minas Gerais, de 25/11/1906, p. 1, col. 2. Autoria atribuída a João Pinheiro da Silva.

${ }^{20}$ SILVA, João Pinheiro da. "Carta de João Pinheiro da Silva a Afonso Pena”. Relata entusiasticamente o ensino agrícola prático na Fazenda da Gameleira, dentre outros assuntos. Belo Horizonte, 16 de março de 1907. In: FUNDO AFONSO PENA (ON). Microfilmes AN 523-2004; AN 536-2004. Arquivo Nacional, Rio de Janeiro.
} 
ao método de ensino empregado: o ensino intuitivo. ${ }^{21} \mathrm{O}$ ensino primário de agricultura pensado para os adultos, que objetivava habituá-los ao simples manejo das aperfeiçoadas máquinas agrícolas, continha duas partes essenciais, uma teórica e outra propriamente industrial. Este ensino havia sido

dividido de modo que uma repartição especial e técnica se incumba da primeira [parte], e a divulgação do trabalho mecânico e dos processos úteis, aconselhados pela teoria, seja feita intuitivamente pelos mestres práticos de cultura, espalhados pelo Estado, operando industrialmente, para que os agricultores possam avaliar das vantagens integrais e da superioridade dos processos novos, comparados com os da velha rotina. ${ }^{22}$

A segunda parte essencial do ensino primário agrícola destinado aos adultos seria ministrada pelas fazendas-modelo e também pelas fazendas subvencionadas e, de forma itinerante, pelos mestres de cultura ambulantes.

A lei 438, de 1906, foi executada pelo decreto 2.027, de 8 de junho de 1907, que reorganizou os serviços da Diretoria da Agricultura, incluindo a regulamentação das fazendas-modelo. Aquele decreto enquadrou esses estabelecimentos em quatro tipos, como pode ser visto no Quadro 1.

Quadro 1 - Tipos de fazendas-modelo, Minas Gerais, 1907

\begin{tabular}{|c|c|l|l|l|}
\hline Tipos & $\begin{array}{c}\text { Tamanho } \\
\text { do terreno }\end{array}$ & \multicolumn{1}{|c|}{ Máquinas agrícolas } & Tração & $\begin{array}{l}\text { Número de } \\
\text { culturas }\end{array}$ \\
\hline A & 10 alqueires & Aratórias & Animal & Um \\
\hline B & 25 alqueires & $\begin{array}{l}\text { Aratórias e de beneficiamento } \\
\text { simples }\end{array}$ & Animal & Dois ou três \\
\hline C & 40 alqueires & Aratórias e de beneficiamento & Hidráulica & Policultura \\
\hline D & 80 alqueires & Aratórias e de beneficiamento & $\begin{array}{l}\text { Hidráulica } \\
\text { ou elétrica }\end{array}$ & $\begin{array}{l}\text { Policultura, laticínios e } \\
\text { produtos florestais }\end{array}$ \\
\hline
\end{tabular}

Fonte: decreto 2.027, 8 de junho de 1907. In: MINAS GERAIS. Coleção das Leis e Decretos do Estado de Minas Gerais, em 1907. Belo Horizonte, Imprensa Oficial de Minas Gerais, 1908, p. 142. Elaboração própria.

As fazendas deveriam diferenciar-se pelo tamanho do terreno e principalmente pelo tipo de máquinas agrícolas utilizadas, a forma de energia

\footnotetext{
${ }^{21}$ Sobre o método intuitivo, ver VALDEMARIN, Vera Teresa. Método intuitivo: os sentidos como janelas e portas que se abrem para o mundo interpretado. In: SOUZA, R.S.; VALDEMARIN, V.T.; ALMEIDA, J.S. 0 legado educacional do século XIX. Araraquara: Ed. da UNESP, 1998, p. 63-105. Sobre o ensino intuitivo na Fazenda-modelo da Gameleira, consultar VERSIEUX, Daniela Pereira. Educação profissional agrícola em Minas Gerais no início do século XX e o ensino de adultos pelo método intuitivo. Boletim Técnico do SENAC: a revista da educação profissional. Rio de Janeiro, v. 38, no 1, jan./abri. 2012. pp. 35-45.

${ }^{22}$ SILVA, João Pinheiro da. Mensagem dirigida pelo presidente do Estado, dr. João Pinheiro da Silva ao Congresso Mineiro. Belo Horizonte: Imprensa Oficial do Estado de Minas Gerais, 1907, p. 5.
} 
empregada e culturas vegetais a serem produzidas. A fazenda do tipo D deveria ser o exemplo para os grandes proprietários rurais. As fazendas-modelo implantadas não obedeceram exatamente a esta divisão de tipos, não sendo esta tão clara como queria o regulamento. A pesquisa empreendida em fontes primárias nos leva a afirmar que nem mesmo chegou-se a implementar uma fazenda-modelo nos moldes do tipo D, de acordo com a documentação do período consultada.

O regulamento baixado com o decreto 2.207/1907 determinou que as fazendas-modelo previstas pela lei 438/1906 deveriam ser instaladas às expensas exclusivas do governo do Estado, excluindo desse número aquelas implantadas por iniciativa das Câmaras Municipais e particulares. Estas últimas, segundo o artigo 55 do mesmo regulamento, deveriam ser "administradas e custeadas pelo Estado diretamente, pertencendo-lhe a propriedade e o respectivo rendimento." ${ }^{23}$ Dessa forma, houve uma ampliação significativa em relação à lei 438/1906, propiciando a instalação de algumas fazendas-modelo que não aquelas previstas na referida lei, sem, contudo, que o seu número fosse mais significativo do que aquele previsto inicialmente.

A proposta de criação das fazendas-modelo, tanto no que observamos no regulamento promulgado com o decreto 2.207/1907, quanto nas discussões da tramitação do projeto n. 167/1906, que deu origem à lei 438/1906, nos leva a inferir que essas fazendas tinham por missão agir como "polos de desenvolvimento" para as diferentes regiões do Estado. Vejamos o porquê disso.

Jonh D. Wirth caracterizou o Estado de Minas Gerais, que ele estudou no período designado como primeira e segunda repúblicas (1889-1937), como um

mosaico de sete zonas diferentes ou sub-regiões [...] Por um lado, este estado heterogêneo, [...] refletia o impulso histórico de outras unidades além das fronteiras políticas da região. Por outro lado, cada zona desenvolveu-se numa linha diferente de tempo, dando ao estado uma longa história de crescimentos desarticulados e descontínuos. ${ }^{24}$

Foi possível ao autor identificar as características decorrentes desse crescimento desigual. Segundo ele, as zonas

\footnotetext{
${ }^{23}$ MINAS GERAIS. Coleção das Leis e Decretos do Estado de Minas Gerais, em 1907. Belo Horizonte, Imprensa Oficial de Minas Gerais, 1908, p. 142.

${ }^{24}$ WIRTH, John D. O fiel da balança: Minas Gerais na Federação Brasileira (1889-1930). Tradução de Maria Carmelita Pádua Dias. Rio de Janeiro: Paz e Terra, 1982, p. 41.
} 
Oeste e o sudoeste, o Triângulo e o Sul são extensões lógicas do interior de São Paulo, ao qual o primeiro esteve ligado juridicamente até 1816, e ao qual todos ainda estão ligados econômica e culturalmente. A maior parte do vale do Rio São Francisco geograficamente faz parte do sertão brasileiro, que se alonga além da Bahia e Pernambuco, atingindo o Ceará. De fato, a parte norte de Minas foi administrada a partir de Salvador, Bahia, até 1750; quase todas as suas exportações atravessam Salvador até o presente século. O Oeste pertencia à fronteira colonial do gado, estendendo-se da Bahia a Goiás. No sudeste, a zona da Mata gravitava para o porto da cidade do Rio de Janeiro, fazendo parte do interior do Rio de Janeiro, desde o início do 'boom' do café em 1830. E, além da fronteira da zona Leste, o pequeno estado do Espírito Santo isolava os mineiros do mar, como era o desejo de Portugal. ${ }^{25}$

Dessa forma, as zonas da Mata, do Sul e Triângulo ligavam-se tradicionalmente aos polos de desenvolvimento do Rio e São Paulo, enquanto as do Norte e Oeste, menos desenvolvidas, "eram extensões da Bahia". ${ }^{26}$ Por fim, a zona do Centro, onde se instalou a sede do governo provincial e, depois, do estadual, isolou-se do resto de Minas. Dali "os governantes viram sua autoridade sobre as outras zonas diminuir pela falta de influência econômica e as parcas comunicações". Além disso, "com suas cidades barrocas do século XVIII, [o Centro] desenvolveu tradições que vieram tipificar a cultura mineira". ${ }^{27}$

Essas assimetrias regionais eram já percebidas pelas elites do início do século XX e nortearam algumas intervenções políticas. O deputado Ignácio Murta, na sessão da Câmara do Congresso Legislativo Mineiro em que se discutia pela terceira vez o projeto n. 167/1906, sugeriu que as fazendas-modelo fossem instaladas nas regiões que não eram servidas por estradas de ferro. A proposição desse parlamentar vinculou-se à discussão do artigo $1^{\circ}$ do mesmo projeto, que previa a instalação de seis colônias agrícolas próximas a estradas de ferro e de navegação fluvial, com o que ele concordava, e também à defesa que o mesmo deputado fazia da construção de estradas de ferro no vasto território do norte de Minas, que correspondia ao que hoje conhecemos como Jequitinhonha, Rio Doce, Noroeste e parte do Alto São Francisco. Tal proposição era mais uma das tentativas legislativas de diminuir o fosso que separava o Norte de outras regiões mais desenvolvidas do Estado. Ignácio Murta defendeu que, como era

\footnotetext{
${ }^{25}$ Ibidem, p. 41-42.

${ }^{26}$ Ibidem, p. 42.

${ }^{27}$ Ibidem.
} 
mais conveniente e de incontestável vantagem o estabelecimento de colônias agrícolas nas proximidades das ferrovias e rios navegáveis, devem as fazendas-modelo, de preferência, ser fundadas naquelas zonas longínquas e até agora esquecidas e privadas de viação rápida e, portanto, sem meios de desenvolverem sua lavoura, comércio e indústria. ${ }^{28}$

Para o deputado, a "vasta e futurosa zona norte-mineira", banhada pelos rios Jequitinhonha, Doce, Mucuri, Araçuaí, Pardo e São Francisco, possuía inesgotáveis riquezas minerais e terras de superior qualidade para todos os tipos de cultura, sendo que

a fundação ali de alguma das fazendas-modelo será de intuitiva vantagem, tanto para a indústria agrícola-pastoril, como a conservação das matas, necessárias para a regularidade das estações, conservação das águas e salubridade do clima. ${ }^{29}$

Dessa forma, na concepção de Ignácio Murta, as fazendas-modelo iriam preparando a zona do norte para receber a "suspirada visita da estrada de ferro", concorrendo para "o desenvolvimento da lavoura e da indústria" ${ }^{30}$ De certa forma seu pedido foi atendido, com a instalação, em setembro de 1907, de uma fazenda-modelo no município do Serro. O regulamento contido no decreto 2.207, de 8 de junho desse ano previa, em seu artigo 49, que as seis fazendas-modelo instaladas por conta do Estado, deveriam localizar-se "uma no centro, uma no norte, uma no sul, uma na zona da mata, uma no triangulo mineiro e uma na zona do oeste." ${ }^{31}$ Dessa forma, o governo estadual pretendeu alcançar o "mosaico" de regiões diferentes do Estado. A grande superfície territorial de Minas Gerais aliada à diversidade política, econômica, populacional, territorial e social entre as regiões e às complexas relações políticas que perpassavam os poderes executivo e legislativo, cuja elite buscava idealmente a "unidade, ainda que fraturada em diversos pontos" 32 , justifica a tentativa de atingir todo o "mosaico". Segundo Wirth (1982) "politicamente, Minas evoluiu como um minissistema federal, o que permitiu que os interesses regionais fossem balanceados e compensados a partir de uma concepção razoável do todo". ${ }^{33}$ A organização em "mosaico"

\footnotetext{
${ }^{28}$ CONGRESSO MINEIRO, op. cit., 1906, p. 284.

${ }^{29}$ Ibidem, p. 284.

${ }^{30}$ Ibidem, p. 286.

${ }^{31}$ MINAS GERAIS, op. cit., 1908, p. 141.

${ }^{32}$ WIRTH, op. cit., p. 66.

${ }^{33}$ Ibidem, p. 67.
} 
nos permite ainda compreender a política descentralizada de ensino agrícola, aqui representada pelas fazendas-modelo.

O decreto 2.207/1907 determinava ainda que a atividade predominante das fazendas-modelo deveria estar de acordo com a competência de cada área: o ensino para o cultivo da terra, nas regiões agrícolas, e o ensino da pecuária, nas regiões pastoris.

Mais significativas, e em sintonia com o discurso - e com o desejo - do deputado Ignácio Murta, foram as prescrições contidas nos artigos 57, 58 e 59 do referido regulamento. Determinavam que o governo mantivesse reprodutores de diversos animais para que os criadores levassem suas fêmeas para cruzamento, melhorando o rebanho do Estado; que mantivesse um estoque de máquinas agrícolas e de beneficiamento, a serem cedidas a preço de custo aos agricultores e colonos das colônias anexas às fazendas-modelo; e que as fazendas-modelo cedessem, por empreitada, trabalhadores agrícolas às fazendas vizinhas, numa tentativa de suprir a demanda por trabalhadores nas lavouras. Em outras palavras, um centro irradiador de progresso e oportunidades para os lavradores e criadores, que se situavam distantes do centro econômico do Estado.

A isso se somava o propósito central das fazendas-modelo, que era ministrar o ensino agrícola-pastoril prático aos trabalhadores e jovens mineiros, mais uma característica potencializadora de progresso econômico regional. Dessa forma, mesmo não aparecendo a expressão "polos de desenvolvimento" nas discussões da lei 438/1906, nem no seu texto legislativo, o fato dos parlamentares usarem a expressão "desenvolvimento", no sentido de progresso econômico das regiões menos adiantadas do Estado, como o próprio norte de Minas, nos autoriza a utilizar a expressão acima, no sentido estrito que os contemporâneos davam ao termo "desenvolvimento".

Contudo, é preciso assinalar que, a despeito dessas discussões ocorridas na Câmara dos Deputados mineiros, as fazendas-modelo foram instaladas em cidades em geral antigas, algumas delas servidas por estradas de ferro e, portanto, com algum grau de desenvolvimento. Além disso, nem todas as zonas tiveram suas fazendas-modelo, como pode ser observado no Quadro 2 e na Figura 1. 
Quadro 2 - Localização, data e instrumento de criação das fazendas-modelo, Minas Gerais, 1906-1914

\begin{tabular}{|l|c|c|c|l|}
\hline Fazendas-modelo & \multicolumn{2}{|c|}{ Localização } & $\begin{array}{l}\text { Data de } \\
\text { criação }\end{array}$ & \multicolumn{1}{|c|}{ Instrumento de criação } \\
\hline Gameleira & Município & Região & & \\
\hline Fábrica & Belo Horizonte & Centro & $26 / 11 / 06$ & $\begin{array}{l}\text { Compra de terrenos pelo gover- } \\
\text { no estadual. }\end{array}$ \\
\hline Retiro do Recreio & Serro & Centro/Norte & $25 / 09 / 07$ & $\begin{array}{l}\text { Decreto 2.099/1907. Compra de } \\
\text { terrenos pelo governo estadual. }\end{array}$ \\
\hline Diniz & Itapecerica & Oeste & $04 / 12 / 07$ & $\begin{array}{l}\text { Decreto 2.131/1907. Doação de } \\
\text { terrenos por particulares. }\end{array}$ \\
\hline Aiuruoca & Centro & $27 / 11 / 07$ & $\begin{array}{l}\text { Decreto 2.129/1907. Doação de } \\
\text { terrenos pela Câmara Munici- } \\
\text { pal de Santa Bárbara. }\end{array}$ \\
\hline Bairro Alto & Campanha & Sul & 27/11/08 & $\begin{array}{l}\text { Decreto 2.201/1908. Doação de } \\
\text { terrenos pela Câmara Munici- } \\
\text { pal de Aiuruoca. }\end{array}$ \\
\hline $\begin{array}{l}\text { Recreto 2.309/1908. Transfe- } \\
\text { para o Estado. }\end{array}$
\end{tabular}

Fontes: Relatórios da Diretoria de Agricultura, 1908 e 1909, legislação mineira, jornal Minas Gerais (19071909). Elaboração própria.

Ao que tudo indica, a escolha dos locais de instalação dessas instituições obedeceu a critérios antes políticos do que econômicos, que estavam, estes últimos, vinculados à busca pelo equilíbrio no desenvolvimento econômico das diversas regiões do Estado. John Wirth salienta que "como região, Minas era definida não apenas por sua base econômica difusa, mas também por seus valores políticos e culturais. O regionalismo mineiro foi primeiramente uma concepção político-cultural, que não engrenava facilmente com os fatores econômicos". ${ }^{34} \mathrm{~A}$ instalação das fazendas-modelo em cidades com algum desenvolvimento, o que é atestado pela presença de estradas de ferro, nos indica que a opção política envolvia também facilidades de fiscalização, circulação de recursos materiais e humanos bem como um menor gasto com a instalação das fazendas-modelo. De fato, ainda é Wirth quem nos indica que "os resultados das diretrizes regionais eram decepcionantes, em parte por causa de deficiências políticas, em parte porque a receita regional era ambígua devido à localização peculiar do Estado e seu modelo de desenvolvimento em mosaico". ${ }^{35}$ Dessa forma, corroborando os

\footnotetext{
${ }^{34}$ Ibidem, p. 69.

${ }^{35}$ Ibidem, p. 70.
} 
resultados de Wirth (1982), a atuação das fazendas-modelo como "polos de desenvolvimento regional" ficou comprometida desde muito cedo.

Inicialmente as fazendas-modelo foram pensadas como instituições de formação secundária, e assim foram definidas nas leis de 1906 (438 e 444). Sena Figueiredo defendeu, durante as discussões do projeto n. 167/1906 na Câmara do Congresso Mineiro, que, nessas fazendas, não poderia faltar

ensino técnico, o ensino pratico propriamente dito, isto é, o ensino de rudimentos de eletricidade, de rudimentos práticos de mecânica, para que o produtor, para que o lavrador adquirindo esses conhecimentos, possa aplicálos na sua propriedade agrícola e não sofra as consequências funestas da sua ignorância, não esteja sujeito aos contratempos que sobrevêm àqueles que não têm noções praticas das matérias que se relacionam com a profissão a que se dedicam. ${ }^{36}$

Figura 1 - Localização dos municípios, em suas respectivas zonas, que abrigaram fazendas-modelo e o campo de demonstração de Aiuruoca. Minas Gerais, 1908-1915

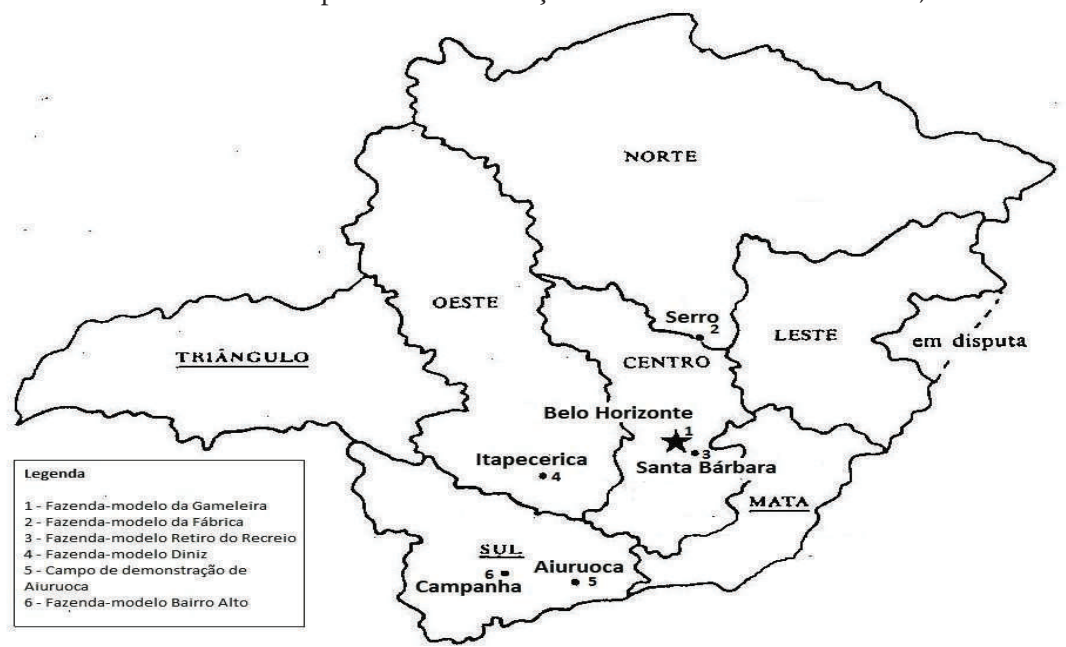

Fonte: Adaptado de John D. Wirth (1982). Este mapa tem por objetivo apresentar de forma aproximada a localização dos municípios que sediaram as instituições pesquisadas.

Entre 1906 e 1909 foram várias as tentativas de se criarem fazendas-modelo, tanto por parte do Estado, quanto pelas municipalidades e até mesmo por particulares. Maria Auxiliadora Faria (1992) indica que

pela lei $n^{\circ} 438$, de 24 de setembro de 1906, o governo foi autorizado a criar 6 fazendas modelo, das quais só 5 foram efetivamente instaladas: Fazenda Modelo da Gameleira, em Belo Horizonte; da Fábrica, no

\footnotetext{
${ }^{36}$ CONGRESSO MINEIRO, op. cit., 1906, p. 416.
} 
Serro; do Retiro do Recreio, em Sta. Bárbara; Diniz, em Itapecerica e Bairro Alto, em Campanha. O regulamento de 1911 ampliou a possibilidade de criação de novas fazendas, desde que conveniadas com os governos municipais. Apesar dos incentivos do Estado às eventuais iniciativas dos municípios, nenhum deles manifestou interesse e o número das fazendas modelo não foi alterado. ${ }^{37}$

Apuramos que, por iniciativa do governo estadual, foram criadas somente três das fazendas-modelo citadas por Maria Auxiliadora Faria: a da Gameleira, a da Fábrica e a do Bairro Alto (ver Quadro 2). As duas primeiras tiveram seus terrenos escolhidos pelo governo mineiro e a última foi criada a partir de uma doação de terras feita pelo governo federal. Além disso, como já visto, a lei 438/1906, promulgada cinco anos antes do regulamento de 1911, citado por Faria, já previa arranjos entre Câmaras Municipais e particulares com o governo estadual. Contudo, o decreto que regulamentou esta lei, o 2.027/1907, não determinou como seriam os acordos entre particulares e Estado. Em todo caso, os municípios poderiam ceder terrenos para que o Estado implantasse as fazendas-modelo. Os entendimentos entre governo estadual e proprietários particulares eram incentivados pela imprensa oficial e a Diretoria de Agricultura terminou por enquadrar as iniciativas particulares de se fundar fazendas-modelo no mesmo artigo 55, do decreto 2.027/1907.

Um daqueles editoriais do jornal Minas Gerais que consideramos terem sido escritos por João Pinheiro explicava que o Congresso Mineiro havia votado verba de 500 contos de réis para auxiliar as municipalidades que quisessem fundar fazendas-modelo. Assim,

por este meio e com tão pequeno sacrifício, o povo verá o que é um arado, um rolo, uma grade e como estas máquinas trabalham e que imensas vantagens as da sua aplicação, e, estabelecido este pequeno núcleo em cada município, não será difícil que a ação se irradie pelos distritos. ${ }^{38}$

O governo mineiro acreditava que, por meio da instalação de fazendas-modelo por iniciativa municipal e particular o ensino agrícola se espalharia pelo Estado, utilizando-se poucos recursos. Pode-se inferir aqui uma tentativa de vulgarização da agronomia a preços módicos, por meio do ensino agrícola. Consideramos que esta concepção, de que o progresso do Estado viria necessariamente com a contribuição e, mais do que isso, com

\footnotetext{
${ }^{37}$ FARIA, Maria Auxiliadora. A Política da Gleba: As Classes Conservadoras Mineiras; discurso e prática na Primeira República. 1992. 394 f. (Tese de Doutorado, História Social). Faculdade de Filosofia, Letras e Ciências Humanas, Universidade de São Paulo, São Paulo, 1992, p. 273.
}

${ }^{38}$ AGRICULTURA - II. Minas Gerais, 10/02/1907, p. 1, col. 1(s/a). Autoria atribuída a João Pinheiro da Silva. 
a participação ativa das municipalidades, vinculou-se à experiência de João Pinheiro na Câmara Municipal de Caeté, no período em que esteve afastado da política mais ampla do Estado. Este político assumiu a presidência da Câmara Municipal e as funções de agente executivo de Caeté em $1^{\circ}$ de janeiro de $1899^{39}$, implantando a partir de então uma série de medidas que apareceriam depois tanto nas teses do Congresso Agrícola de $1903^{40}$ quanto em seu manifesto-programa, como candidato à presidência do Estado de Minas Gerais. Instituiu, por exemplo, prêmios de produção agrícola e pastoril à iniciativa privada e organizou a I Feira Municipal de Caeté, ocorrida em setembro de $1902 .{ }^{41}$ No manifesto-programa de sua candidatura à presidência de Minas, declarou que esperava ser

eficazmente auxiliado pelos governos municipais. Eles gozam na República e principalmente em Minas, de ampla liberdade de ação; acham-se em contato direto com o povo, e, portanto, devendo realizar, em menor esfera, o mesmo pensamento que inspira o Governo do Estado, cuidando mais de administração e menos de política, ou seguindo a verdadeira política. [...]

Que a renda municipal seja aplicada em obras públicas, [...]; que se estabeleçam prêmios para o incentivo e aumento da produção; que se reduza ao mínimo o funcionalismo municipal; [...]

Semelhante política fará que as localidades prosperem, sendo resultante a prosperidade do Estado. ${ }^{42}$

As andanças de João Pinheiro pelo interior do Estado, principalmente durante os anos de 1906 e 1907, corroboram essa percepção. João Pinheiro, antes da sua posse como presidente do Estado empreendeu uma excursão, em junho de 1906, "por diversos municípios da Zona da Mata, sem aviso prévio, sem se fazer acompanhar de comitiva e sem qualquer protocolo". ${ }^{43}$ E, após tornar-se chefe do executivo mineiro, participou dos congressos das municipalidades ocorridos nas zonas mineiras do Sul, Norte e da Mata. ${ }^{44}$

\footnotetext{
${ }^{39}$ Cf. BARBOSA, op. cit.

${ }^{40}$ Congresso Agrícola, Comercial e Industrial ocorrido entre os dias 13 e 19 de maio de 1903, em Belo Horizonte, em meio à primeira crise de superprodução do café, que durou de 1897 a 1909 (DULCI, 2005; FARIA, 1992). Reunindo, pela primeira vez, as classes produtoras e a elite intelectual mineiras, foi patrocinado pelo governo de Francisco Sales (1902-1906). Esta reunião objetivou realizar um rigoroso diagnóstico da realidade contemporânea, regional e nacional, a partir da qual foi traçado um projeto de desenvolvimento econômico para o Estado (FARIA, op. cit., 1992).

${ }^{41}$ BARBOSA, op. cit., 1980.

${ }^{42}$ SILVA, João Pinheiro. "Ao povo mineiro". In: BARBOSA, Francisco de Assis. As Ideias Políticas de João Pinheiro: cronologia, introdução, notas bibliográficas e textos selecionados. Brasília: Senado Federal/MEC; Rio de Janeiro: Fundação Rui Barbosa, 1980, p. 195.

${ }^{43}$ BARBOSA, op. cit., 1980, p. 22.

${ }^{44}$ O Congresso das Municipalidades do Sul ocorreu em Itajubá, entre os dias 26 e 28 de abril de 1907; o das Municipalidades do Norte reuniu-se na cidade de Diamantina, entre 20 e 22 de setembro do mesmo ano;
} 
Em um editorial do jornal Minas Gerais conclamou as municipalidades a se unirem ao Governo nessa empreitada, solicitando a elas que concorressem “com o mínimo de terras e subvenção [...] e se terá generalizado por todo Estado o ensino e o emprego das máquinas agrícolas. Não vale a pena o sacrifício por parte das municipalidades?" 45

Algumas municipalidades atenderam ao apelo do governo mineiro. Pudemos localizar, por meio do jornal oficial Minas Gerais, quinze iniciativas locais para a fundação de fazendas-modelo que não se efetivaram, sendo doze tentativas por parte das Câmaras Municipais e três iniciativas particulares (ver Quadro 3). Apesar de a verba ter sido votada e as terras terem sido oferecidas pelas municipalidades e por particulares, as iniciativas não foram transformadas em realidade, em boa parte dos casos. Em outras palavras, a maioria das tentativas de se implantar fazendas-modelo, por essa via, não resultou em efetivação deste tipo de estabelecimento e fracassaram.

Quadro 3 - Iniciativas locais para se criar fazendas-modelo, Minas Gerais, 1907-1909

\begin{tabular}{|l|l|c|}
\hline \multicolumn{1}{|c|}{ Município } & \multicolumn{1}{c|}{ Iniciativa } & $\begin{array}{c}\text { Data da edição do } \\
\text { jornal Minas Gerais }\end{array}$ \\
\hline Santa Luzia do Rio das Velhas & Particular. Grupo Agrícola de Traíras & $19 / 10 / 1906$ \\
\hline Ouro Fino & Câmara Municipal & $22 / 02 / 1907$ \\
\hline Santa Bárbara(1) & Câmara Municipal & Junho/1907 \\
\hline Cataguases & Câmara Municipal & $10 / 07 / 1907$ \\
\hline Cambuí & Câmara Municipal & $10 / 07 / 1907$ \\
\hline Itapecerica & Particular - Lamounier Godofredo & $03 / 08 / 1907$ \\
\hline Aiuruoca (1) & Câmara Municipal & Novembro/1907 \\
\hline Itapecerica ${ }^{(2)}$ & $\begin{array}{l}\text { Particular - Major Ignácio Ferreira } \\
\text { Diniz e Beralda Rita Diniz }\end{array}$ & $08 / 11 / 1907$ \\
\hline Cristina & Câmara Municipal & $02 / 11 / 1907$ \\
\hline Uberaba & Câmara Municipal & $02 / 11 / 1907$ \\
\hline-- & $\begin{array}{l}\text { Particular - Coronel Francisco de } \\
\text { Oliveira }\end{array}$ & $02 / 12 / 1907$ \\
\hline Dores do Indaiá & Câmara Municipal & $30-31 / 12 / 1907$ \\
\hline Araguari & Câmara Municipal & $26 / 03$ e 21/12/1908 \\
\hline Ponte Nova & Câmara Municipal & $11-12 / 05 / 1908$ \\
\hline Santa Rita da Extrema & Câmara Municipal & $09 / 07 / 1908$ \\
\hline Alvinópolis & Câmara Municipal & $12 / 08 / 1908$ \\
\hline Juiz de Fora & Câmara Municipal & $21-22 / 12 / 1908$ \\
\hline Peçanha & Câmara Municipal & $04 / 06 / 1909$ \\
\hline
\end{tabular}

Fonte: Jornal Minas Gerais, setembro/1906-março/1915. Elaboração própria.

${ }^{(1)}$ As datas apresentadas para as duas iniciativas referem-se ao início do processo de doação das terras pelas municipalidades, que culminaram na criação de duas fazendas-modelo.

${ }^{(2)}$ Esta data refere-se ao dia em que os terrenos foram efetivamente doados.

já o Congresso da Mata foi instalado na cidade de Leopoldina, entre os dias 12 e 14 de outubro de 1907. Conforme BARBOSA, op. cit., 1980.

${ }^{45}$ AGRICULTURA - II. Minas Gerais, 10/02/1907, p. 1, col. 2 (s/a). Autoria atribuída a João Pinheiro da Silva. 
Além dessas três iniciativas municipais obtiveram sucesso. A fazenda-modelo Diniz, em Itapecerica, instituída por decreto, foi criada a partir da doação de terrenos por particulares da cidade. Já a fazenda Retiro do Recreio, em Santa Bárbara, e o campo de demonstração de Aiuruoca, situado nos arredores da cidade de mesmo nome, foram instituídos também por decreto, tendo como ponto de partida os terrenos doados pelas respectivas Câmaras municipais (QUADROS 2 e 3).

O jornal Minas Gerais noticiou, em 19 de setembro de 1906, data anterior à daquelas iniciativas locais listadas no QUADRO 3, que havia chegado às mãos do novo presidente do Estado "as propostas de sete municipalidades mineiras, no sentido de se estabelecerem nos respectivos municípios as fazendas modelo". ${ }^{46}$ Esse dado eleva para vinte e cinco as tentativas municipais de se instalar fazendas-modelo, incluindo aí aquelas que efetivamente foram implantadas. Tal situação indica-nos que a criação de fazendas-modelo no Estado despertou senão o entusiasmo, mas ao menos o interesse das autoridades municipais. Esse interesse ficou explícito, por exemplo, na notícia divulgada por um jornal de Uberaba e transcrita pelo Minas Gerais:

a notícia, que fomos os primeiros a dar, de instalação de uma fazenda-modelo em Uberaba, parece que caminha para uma brilhante realidade.

Há poucos dias esteve aqui o sr. Nunzio Gianatazio, mestre de cultura do Estado, [...] [que] visitou demoradamente o ex-Instituto Zootécnico [...] [Ele] teve agradável impressão do local, apenas considerando ser pequena a extensão de terra cedida, que é de 10 alqueires apenas. ${ }^{47}$

Levando-se em consideração essa última afirmação, a proposta não se consolidou por ser insuficiente o tamanho da propriedade oferecida pela municipalidade. Outra proposta, a da Câmara de Dores do Indaiá, previu até mesmo dotação orçamentária, mas não conseguimos saber por que não foi aceita. Pudemos averiguar que outras tentativas não deram resultados concretos devido ao fato de que os terrenos oferecidos não satisfazerem as condições necessárias para a fundação de uma fazenda-modelo. Porém, nem sempre se indicou qual ou quais condições não foram satisfeitas. De maneira geral, a Diretoria de Agricultura, ao aprovar a instalação de fazendas-modelo em terrenos cedidos por particulares ou Câmaras Municipais, avaliou que estes possuíam uma parte de terrenos planos ou pouco inclinados, o que permitiria a utilização de máquinas agrícolas aratórias, e dispunham de água

\footnotetext{
${ }^{46}$ AS FAZENDAS MODELOS. Minas Gerais, 19/09/1906, p. 6, col. 3 (s/a).

${ }^{47}$ FAZENDA MODELO. Minas Gerais, 08/11/1907, p. 6, col. 2 (s/a).
} 
suficiente para irrigação de lavouras. Após 1909, mesmo antes, portanto, do regulamento aprovado em 1911, não mais foram criadas fazendas-modelo, apesar das tentativas que relatamos.

Daquelas que chegaram a ser criadas, em lei ou de fato, identificamos sete. Dessas, apenas a fazenda-modelo D. Antônia Augusta, instituída pelo decreto n. 2.113, de 14 de outubro de 1907, no município de Leopoldina, não deve ter sido de fato instalada. Das poucas referências encontradas sobre esta fazenda, conseguimos apurar que sua área, pertencente à Câmara Municipal de Leopoldina, foi adquirida por 6:000\$000 (seis contos de réis). Em seguida, foi anexada à colônia de povoamento Barão de Aiuruoca, situada no município de Mar de Espanha, pela necessidade de se aumentar os terrenos da mesma.

A fazenda-modelo de Aiuruoca foi transformada, pelo decreto n. 2.262 de 12 de agosto de 1908, em campo de demonstração, tendo uma existência efêmera enquanto fazenda-modelo. Entretanto, o campo de demonstração existiu até 1919, e escapou de ser arrendado ou vendido quando do fim das fazendas-modelo, apesar de em tudo similar. Aqui, é necessário demarcar os limites entre fazendas-modelo e os campos de demonstração, justificando a inclusão do campo de demonstração de Aiuruoca nesta pesquisa, que se concentra nas fazendas-modelo. Esta justificativa extrapolou o fato de ele ter sido criado como fazenda-modelo.

O decreto federal n. 8.319, de 20 de outubro de $1910^{48}$, que criou o Ensino Agronômico no Brasil, indica que os "campos de experiência e demonstração" seriam "serviços e instalações complementares" às diversas "divisões" do Ensino Agronômico: ensino superior, ensino médio ou teórico-prático, aprendizados agrícolas, escolas especiais de agricultura, escolas domésticas agrícolas (para mulheres), cursos ambulantes, cursos conexos com o ensino agrícola e conferências e consultas agrícolas. O mesmo decreto, ao caracterizar as "fazendas experimentais", também complementares ao ensino agrícola, nos indica que estas seriam muito próximas à forma concreta pela qual se materializou as fazendas-modelo em Minas Gerais. Tal decreto, em seu artigo 428, indica que estas seriam

destinadas ao ensino prático da agricultura, em seus diferentes ramos, por meio de demonstrações de culturas sistemáticas das plantas úteis" e que

\footnotetext{
${ }^{48}$ BRASIL. Decreto $\mathrm{n}^{\circ}$ 8.319, de 20 de outubro de 1910. Cria o ensino agronômico e aprova o respectivo regulamento. Rio de Janeiro, 20 de outubro de 1910. Disponível em: http://www2.camara.leg.br/legin/ fed/decret/1910-1919/decreto-8319-20-outubro-1910-517122-norma-pe.html. Acesso em 25 de abril de 2013.
} 
deveriam "ser estabelecidas como explorações agrícolas de caráter particular com todas as dependências e instalações próprias a uma fazenda modelo, instalada em condições de obter o maior rendimento possível de cultura do solo, da pecuária e das indústrias rurais, e regidas por um serviço completo de contabilidade agrícola. ${ }^{49}$

$\mathrm{Na}$ literatura referente ao período estudado, pode-se perceber uma indistinção entre os termos fazenda-modelo e campo de demonstração. Maria Auxiliadora Faria (1992) diferencia esses dois tipos de estabelecimentos, mas descrevendo-os de maneira muito próxima, sendo ambos definidos como instituições de ensino agrícola prático. Os campos de demonstração eram, de acordo Faria (1992), responsabilidade das municipalidades, pois, "segundo o Regulamento de 1911, elas deviam concorrer com terrenos apropriados e significativas quantias financeiras, cabendo ao governo estadual a supervisão técnica"..$^{50}$ Porém, os campos de demonstração existiram muito antes desse regulamento e foram instalados por iniciativa do Estado ainda no século XIX.51

Ao comparar esses tipos de estabelecimentos que existiram em fins do século XIX e as fazendas-modelo do início do século XX, Versieux (2010) elenca diversas diferenças entre eles. $O$ tipo de organização, estrutura de ensino, o currículo que oscilou de essencialmente prático a teórico-prático. Pode-se ressaltar que o que diferenciou as fazendas-modelo dos campos de demonstração foram as singularidades de cada uma dessas experiências históricas que, mesmo próximas no tempo, foram resultado de políticas distintas, mesmo que complementares.

Identificamos os campos de demonstração com uma política de ensino agrícola centrada na aprendizagem por meio da demonstração das técnicas e processos modernos de agricultura. Nas fazendas-modelo, a aprendizagem centrou-se na demonstração da viabilidade produtiva das mesmas técnicas. Além disso, os campos de demonstração que existiram a partir da assunção de João Pinheiro à presidência do Estado foram, com exceção do de Aiuruoca, instalados como anexos a colônias de povoamento. Podemos citar aqueles que existiram nas colônias de Nova Baden, Itambacuri e Francisco Sales. Dessa forma, por compreender que no campo de demonstração de Aiuruoca a aprendizagem tinha por base a produção agrícola, incluímos este estabelecimento no presente estudo.

\footnotetext{
${ }^{49}$ Idem.

${ }^{50}$ FARIA, op. cit., 1992, p. 282.

${ }^{51}$ VERSIEUX, op. cit., 2010.
} 
As fazendas-modelo tiveram uma existência de fato, e não apenas nos textos emanados do legislativo ou do executivo. Foram administradas pela Diretoria de Agricultura e não tiveram uma existência isolada umas das outras. Ao contrário, a pesquisa empírica revelou que a Diretoria de Agricultura imprimiu um caráter de rede entre as fazendas-modelo e destas com outros estabelecimentos, como os campos de demonstração, campos de experiências, os institutos, aprendizados e colônias agrícolas. Assim, foi possível compreendê-las nessa rede, por onde circulavam funcionários da Diretoria, fazendeiros, aprendizes, trabalhadores, informações, conhecimentos e produtos agrícolas e pastoris.

A característica de rede dada ao ensino agrícola não foi exclusiva do Estado mineiro. Pode-se citar a existência em São Paulo, no mesmo período por nós aqui estudado, de diversas instituições vinculadas ao ensino agrícola paulista, dispersas por todo o Estado, tais como o Instituto Agronômico de Campinas, campos de experiências e demonstrações em diversos municípios, o Horto Agrário Tropical, de Cubatão, Horto Botânico, Posto Zootécnico Central, Serviço Meteorológico e Galeria de Demonstração de Máquinas, na capital, além da Escola Prática de Agricultura Luiz de Queiroz, em Piracicaba. Dessa ampla rede faziam parte também os serviços de distribuição de mudas e sementes, de propaganda agrícola, a publicação de algumas revistas especializadas e as novas colônias que paulatinamente foram surgindo. ${ }^{52}$

Mesmo integradas a uma rede de propaganda e ensino agrícola primário e elementar, as fazendas-modelo não obedeceram, do mesmo modo, às orientações político-administrativas emanadas da legislação estadual e da Diretoria de Agricultura. As orientações dessa Diretoria, captadas principalmente por meio de seu expediente publicado no Jornal Minas Gerais, eram relativas a admissão de aprendizes, realização de serviços nas fazendas-modelo, prestação de contas, envio de máquinas agrícolas, admissões e demissões de funcionários, além de ameaças de punições aos mesmos. Em relação à questão dos aprendizes, pode-se exemplificar uma dessas orientações de fins de 1911, quando a Diretoria de Agricultura declarou aos encarregados das fazendas Diniz, Fábrica, Retiro do Recreio e Bairro Alto, que "devem admitir aprendizes nas fazendas que respectivamente administram e, bem assim, tomar sempre nota das pessoas que as visitarem". ${ }^{5}$

\footnotetext{
${ }^{52}$ FERRARO, op. cit., 2005.

${ }^{53}$ DIRETORIA DE AGRICULTURA, TERRAS E COLONIZAÇÃO. SEÇÃO DE AGRICULTURA. Expediente. Minas Gerais, 31/12/1911, p. 2, col. 1 .
} 
Considerando-se os aprendizes a mestres de cultura, somente a fazenda-modelo da Gameleira formou-os. ${ }^{54}$ As demais fazendas-modelo receberam aprendizes trabalhadores e deu-lhes instrução técnica aligeirada. Receberam também diversos visitantes, umas mais, outras menos. Do que foi possível apurar, foi pequena a frequência de aprendizes e talvez de fazendeiros que as visitaram, em comparação com a fazenda-modelo da Gameleira. Se as ordens relativas aos aprendizes foram seguidas, os documentos se perderam. Quanto aos visitantes, não nos foi possível mensurá-los ou qualificá-los, a não ser aqueles que frequentaram a fazenda-modelo da Gameleira, assim mesmo de forma precária. ${ }^{55}$

Na Tabela 1 relacionamos o número de aprendizes em cada fazenda-modelo e no campo de Aiuruoca, entre 1907 e 1914. As informações desse quadro diferem um pouco daquelas elencadas por Maria Auxiliadora Faria. ${ }^{56}$

Tabela 1 - Número de aprendizes das fazendas-modelo do Estado de Minas Gerais, 19071914

\begin{tabular}{|c|c|c|c|c|c|c|c|}
\hline \multirow[b]{2}{*}{ Anos } & \multicolumn{6}{|c|}{ FAZENDAS-MODELO } & \multirow[b]{2}{*}{$\begin{array}{l}\text { Total } \\
\text { anual }\end{array}$} \\
\hline & Gameleira & Fábrica & Retiro do Recreio & Aiuruoca & Diniz & $\begin{array}{c}\text { Bairro } \\
\text { Alto }\end{array}$ & \\
\hline 1907 & 51 & -- & 7 & -- & 4 & - & 62 \\
\hline 1908 & 50 & -- & -- & -- & -- & -- & 50 \\
\hline 1909 & 30 & -- & -- & -- & 18 & -- & 48 \\
\hline 1910 & 23 & 3 & -- & 7 & 13 & -- & 46 \\
\hline 1911 & 14 & 3 & .... & -- & 1 & -- & 16 \\
\hline 1912 & 29 & 4 & 1 & $40^{(1)}$ & -- & 4 & 38 \\
\hline 1913 & 19 & 2 & -- & 5 & -- & 2 & 28 \\
\hline \multirow[t]{2}{*}{1914} & 17 & -- & 4 & -- & -- & -- & 21 \\
\hline & 233 & 12 & 12 & 12 & 36 & 6 & 309 \\
\hline
\end{tabular}

Fontes: DIRETORIA DE AGRICULTURA, COMÉRCIO, TERRAS E COLONIZAÇÃO. Relatórios anuais referentes aos anos de 1907-1909. Belo Horizonte: Imprensa Oficial do Estado de Minas Gerais. 1908-1910. DIRETORIA DE AGRICULTURA, COMÉRCIO, TERRAS E COLONIZAÇÃO. Relatórios anuais referentes aos anos de 19101914. In: SECRETARIA DA AGRICULTURA, INDÚSTRIA, TERRAS, VIAÇÃO E OBRAS PÚBLICAS. Relatórios anuais referentes aos anos de 1910-1914. Belo Horizonte: Imprensa Oficial do Estado de Minas Gerais. 19111915. Elaboração própria.

(1) Este número não é exato, pois se refere aos lavradores que visitaram o campo de demonstração e também àqueles que lá estiveram para aprenderem os aperfeiçoados métodos agrícolas. Por esse motivo não foi computado no total de aprendizes daquele ano, e nem naquele referente à Aiuruoca.

\footnotetext{
${ }^{54}$ VERSIEUX, op. cit., 2012.

${ }^{55}$ VERSIEUX, op. cit., 2010.

${ }^{56}$ FARIA, op. cit., 1992, p. 276.
} 
Assim, para os anos de 1910 a 1914, Faria apurou o número de 103 aprendizes para a Gameleira, treze para a Fábrica e nenhum para as outras fazendas-modelo. De acordo com a Tabela 1, para o mesmo período considerado por Faria, encontramos também 103 aprendizes na Gameleira, doze na Fábrica, cinco na Retiro do Recreio, treze na fazenda-modelo Diniz e seis na do Bairro Alto, além de incluirmos o campo de demonstração de Aiuruoca, que teve 12 aprendizes no período estudado. Atribuímos esta diferença às fontes utilizadas, pois Faria cita apenas os relatórios da Secretaria da Agricultura, ao passo que, para o presente estudo, consultamos também os relatórios da Diretoria de Agricultura, que se revelaram em geral mais completos.

Durante um período de oito anos, pois, encontramos mais de 300 aprendizes que foram treinados para o uso das máquinas agrícolas, sendo que vários destes se tornaram mestres de cultura que se tornaram empregados do Estado e contribuíram para a disseminação dos novos métodos de lida com a terra.

Além da movimentação de aprendizes, os mestres de cultura formados pela Gameleira atuaram nas diversas instituições de educação profissional que fizeram parte da rede de propaganda e ensino agrícola conduzida pela Diretoria de Agricultura. Outro aspecto dessa rede refere-se às máquinas agrícolas. A política de substituição de parcela dos trabalhadores por máquinas, aliada à oferta aprendizado agrícola a alguns trabalhadores, levou o governo mineiro a investir na distribuição de máquinas agrícolas.

A partir de 1907, as assim chamadas modernas máquinas agrícolas, que já eram compradas diretamente pelo Estado, passam a ser sistematicamente adquiridas pelo almoxarifado da Diretoria de Agricultura, não apenas para suprir os estabelecimentos oficiais de ensino e experimentação agrícola, mas sobretudo com a finalidade de serem revendidas a particulares pelo preço de custo, com o frete subsidiado pelo governo. A introdução de máquinas agrícolas no Estado, por iniciativa governamental, deu-se a partir do governo do presidente estadual Crispim Jacques Bias Fortes, entre 1894 e 1898, quando Francisco Sá era o secretário da Agricultura. ${ }^{57}$ De 1907 a 1915, foram 14.108 máquinas adquiridas e cedidas pela Diretoria de Agricultura, tanto aos estabelecimentos mantidos pelo Estado, quanto a proprietários particulares, além de 813 que foram adquiridas diretamente pelos

${ }^{57}$ CARNEIRO, Plinio (coord.). A Agropecuária mineira: sua história, sua evolução. Belo Horizonte: Secretaria de agricultura do Estado de Minas Gerais, s/d. 146 p. 
fazendeiros e transportadas gratuitamente pela mesma Diretoria, como pode ser visto na Tabela. 2.

Esses números foram usados em diversos documentos para comprovar a eficácia do ensino prático de agricultura ministrado nas fazendas-modelo do Estado, particularmente na da Gameleira. Em fins de 1907 um artigo do jornal Minas Gerais dava a conhecer que "nos anos anteriores [a 1907], apesar de ser antiga a medida da venda de máquinas pelo Governo, não chegou a ser vendida a vigésima parte da quantidade saída este ano". ${ }^{58}$ Um número talvez exagerado, a confiar em outro artigo do mesmo jornal, que publicou os seguintes números em relação à venda dessas máquinas pelo governo: 169 unidades em 1904, 116 em 1905 e 160 em 1906 ${ }^{59}$, perfazendo um total de 445 máquinas em três anos.

Tabela 2 - Introdução de máquinas agrícolas no Estado de Minas Gerais, 1907-1915

\begin{tabular}{l|c|c|r}
\hline Anos & $\begin{array}{c}\text { Adquiridas e cedidas pela } \\
\text { Diretoria de Agricultura }\end{array}$ & $\begin{array}{c}\text { Adquiridas pelo agricultor e transportadas } \\
\text { pela Diretoria de Agricultura }\end{array}$ & Total \\
\hline 1907 & 799 & -- & 799 \\
1908 & 1.743 & 87 & 1.830 \\
1909 & 1.874 & 218 & 2.092 \\
1910 & 1.636 & 72 & 1.708 \\
1911 & 1.304 & 95 & 1.399 \\
1912 & 1.240 & 54 & 1.294 \\
1913 & 1.304 & 140 & 1.414 \\
1914 & 1.965 & 122 & 2.087 \\
1915 & 2.243 & 55 & 2.298 \\
& $\mathbf{1 4 . 1 0 8}$ & $\mathbf{8 1 3}$ & $\mathbf{1 4 . 9 2 1}$ \\
\hline
\end{tabular}

Fonte: DIRETORIA DE AGRICULTURA. Relatório apresentado ao Sr. Secretário da Agricultura, Indústria, Terras, Viação e Obras Públicas pelo Diretor de Agricultura, Indústria, Terras e Colonização e referente ao ano de 1918. Belo Horizonte: Imprensa Oficial, 1919, p. 8. Adaptada.

Em outras palavras, o governo imputava ao ensino e à propaganda agrícola a responsabilidade pela introdução massiva, para a realidade da época, de maquinários agrícolas, substituindo homens por máquinas. Essa avaliação é questionável, visto relacionar apenas duas variáveis do problema: o ensino técnico e a introdução de máquinas, desconsiderando, por exemplo, os movimentos mais gerais da economia estadual e nacional. Contudo, essa avaliação pode ter desempenhado papel importante no reforço do ideal representado pelo crescimento da economia agrícola via ensino profissional.

\footnotetext{
${ }^{58}$ DESENVOLVIMENTO AGRÍcOLA DE MINAS GERAIS. Minas Gerais, 5/12/1907, p. 2, col. 2 (s/a).

${ }^{59}$ CONTRA A ROTINA. Minas Gerais, 22-23/06/1908, p. 5, col. 3 (s/a).
} 
Algumas fazendas-modelo tiveram sua atuação ampliada, a partir do final de 1908. Passaram a contar com postos zootécnicos, destinados à aclimatação ${ }^{60}$ e reprodução de animais de raça. Esses animais destinavam-se à venda a particulares, como forma de melhorar os rebanhos do Estado, atingindo, assim, melhores preços nos mercados. Também algumas dificuldades se prolongaram, como o abastecimento de água. Consequentemente as obras de adaptação das fazendas à exploração agrícola e/ou pecuária se estenderam por anos, não ficando restritas aos seus primeiros tempos de instalação, como previra o governo estadual. Assim, caracterizaram a rede de propaganda e ensino agrícola a circulação de animais de criação e reprodução, a aplicação de recursos em obras de infraestrutura e, como se verá, as dificuldades e problemas enfrentados pelos serviços de ensino agrícola.

Tabela 3 - Área total e ocupada por plantações nas fazendas-modelo, Minas Gerais, 1907-1914

\begin{tabular}{l|c|c|c|c|c|c}
\hline \multicolumn{1}{c|}{ Fazendas-modelo } & Gameleira & Fábrica & $\begin{array}{c}\text { Retiro do } \\
\text { Recreio }\end{array}$ & Diniz & Aiuruoca & $\begin{array}{c}\text { Bairro } \\
\text { Alto }\end{array}$ \\
\hline $\begin{array}{l}\text { Tamanho da propriedade } \\
\text { (em alqueires }{ }^{(1)} \text { ) }\end{array}$ & 44 & 25 & 100 & 15 & 15 & 300 \\
$\begin{array}{l}\text { Área ocupada com plantações } \\
\text { (em alqueires) }\end{array}$ & 10,33 & 6,6 & 6,6 & 5,57 & 2,52 & 6,2 \\
$\begin{array}{l}\text { Área ocupada com plantações } \\
\text { em relação à área total do } \\
\text { terreno }\end{array}$ & $23,50 \%$ & $26,40 \%$ & $6,60 \%$ & $37,13 \%$ & $16,80 \%$ & $2,06 \%$ \\
\hline
\end{tabular}

Fontes: DIRETORIA DE AGRICULTURA, COMÉRCIO, TERRAS E COLONIZAÇÃO. Relatórios anuais referentes aos anos de 1907-1909. Belo Horizonte: Imprensa Oficial do Estado de Minas Gerais. 1908-1910. DIRETORIA DE AGRICULTURA, COMÉRCIO, TERRAS E COLONIZAÇÃO. Relatórios anuais referentes aos anos de 19101914. In: SECRETARIA DA AGRICULTURA, INDÚSTRIA, TERRAS, VIAÇÃO E OBRAS PÚBLICAS. Relatórios anuais referentes aos anos de 1910-1914. Belo Horizonte: Imprensa Oficial do Estado de Minas Gerais. 19111915. Os valores apresentados sofreram alterações de ano para ano e correspondem à maior área ocupada entre os anos de 1907 e 1914. Elaboração própria.

(1) $\mathrm{O}$ alqueire mineiro, ainda hoje utilizado, corresponde a 48.400 metros quadrados. Há variações dessa medida, mas assumi-a $\left(48.000 \mathrm{~m}^{2}\right)$ como base de comparação neste estudo. As diferentes unidades de medida usadas para um mesmo terreno - hectares, alqueires e metros quadrados, quando convertidas de acordo com a medida do "alqueire mineiro", corroboram esse uso.

Os problemas administrativos foram comuns. Em algumas fazendas-modelo teve-se uma alta rotatividade de administradores, em outras, mais estabilidade. De forma geral, as substituições de administradores foram efetuadas depois da expedição de vários ofícios, solicitando cuidados com

\footnotetext{
${ }^{60}$ Esse termo referia-se à “adaptação dos animais estrangeiros aos climas de Minas Gerais [...] que consistia em manter o animal por um período de tempo em uma fazenda, até ele se acostumar ao novo ambiente e voltar a engordar, dar leite etc." (VERSIEUX, op. cit., 2010, p. 87).
} 
a prestação de contas, o envio de documentos comprobatórios dos gastos efetuados, proibindo gastos não autorizados. Outra questão administrativa dizia respeito às dificuldades de pagamentos. Houve coletores estaduais, da Secretaria das Finanças, que se recusavam a repassar a verba autorizada para as fazendas-modelo. Até 1910, as fazendas-modelo possuíam dois ou mais auxiliares de administração, mas vários foram demitidos então, em setembro/outubro, quando da restauração da Secretaria da Agricultura. Também foram recomendadas contenções de despesas em fins de 1910.

A despeito dessas semelhanças, muitas eram as diferenças entre as fazendas-modelo, que ressaltamos na Tabela 3. Variou o tamanho das propriedades, a área ocupada por plantações. Variaram também as trajetórias e as relações que cada instituição estabeleceu com a sociedade local e os órgãos de governo. Tais dinâmicas próprias de cada fazenda-modelo não serão apresentadas neste artigo, pela sua própria limitação.

Dessa política pública para o ensino profissional agrícola forjada no início do século XX é possível algumas considerações finais. Pelas fazendas-modelo, enquanto instituições de ensino agrícola profissional, voltadas para um público adulto e trabalhador, passaram cerca de trezentos aprendizes, resultando daí alguma contribuição à formação da mão de obra do campo e para o campo, sobretudo. Ressaltamos que das cinco fazendas-modelo que existiram de fato, apenas a fazenda-modelo da Gameleira cumpriu efetivamente o papel de formadora de pessoal para as lidas agrárias e pastoris.

As fazendas-modelo tiveram seu papel de "polos de desenvolvimento regional" preterido pelas escolhas políticas da época, pois existiram em municípios que já possuíam alguma infraestrutura e maior desenvolvimento econômico em relação a grande parte do Estado de Minas Gerais. A região Leste permaneceu isolada e isolando o Estado, não tendo nenhum investimento público em termos de ensino agrícola no período estudado. 0 vasto Norte também, a não ser pela fazenda-modelo da Fábrica, instalada no município do Serro, porta de entrada para esta região, estando mais próxima do Centro do que do Norte propriamente dito. A Mata, em seu relativo declínio e sob a influência direta da capital do País, também permaneceu sem fazendas-modelo. O Sul e o Centro de Minas Gerais foram as regiões mais beneficiadas, com a implantação de quatro das seis fazendas-modelo instituídas pelo poder público estadual. E o Oeste conquistou sua fazendamodelo, por meio da doação de terras por particulares da região.

Assim, em alguma medida as fazendas-modelo puderam contribuir para o desenvolvimento das localidades onde foram instaladas, uma vez que 
trouxeram, via rede de propaganda e ensino agrícola, recursos humanos e materiais aos agricultores e fazendeiros das regiões onde estavam inseridas.

A circulação de funcionários públicos, fazendeiros, aprendizes, informações, conhecimentos e produtos agrícolas e pastoris pelas diversas instituições de ensino agrícola existentes no período em Minas Gerais, que caracterizou tal rede, necessita de estudos mais aprofundados, não se esgotando nos limites da pesquisa aqui relatada. Isso implica um movimento de apreensão das implicações dessa rede para o desenvolvimento do ensino agrícola em diálogo com movimentos semelhantes empreendidos por outros Estados e pelo Governo Federal durante a Primeira República.

Podemos ressaltar também que houve um distanciamento entre o ensino agrícola proposto, particularmente por Bernardino de Sena Figueiredo, que defendeu um ensino profissional de nível médio, e o ensino agrícola efetivado pelo governo mineiro, de cunho prático. Essa opção política do governo estadual vinculou-se à necessidade de expansão dos capitais agrícolas. Dessa forma, as fazendas-modelo voltaram-se essencialmente para a produção, ensejando a melhoria da qualidade e aumento da produtividade no setor agropecuário, a diminuição de custos, a substituição de parcela dos trabalhadores por máquinas e a qualificação dos trabalhadores que se destinavam às lidas agrárias.

Houve, assim, um deslocamento da formação teórico-prática, representada pelos campos de demonstração de fins do século XIX, em direção a uma formação meramente prática, relegando os aprendizes a operários agrícolas a um aprendizado instrumentalizador, que os destinava a ocupações subalternas no sistema de produção agrícola. Esse movimento conceitual legitima a história do ensino profissional no Brasil, reservado àqueles que não dispunham de recursos e aos chamados "desvalidos da sorte".

A proposição e implantação das fazendas-modelo ligou-se a uma política mais ampla do Estado de Minas Gerais, que envolveu a modernização da agricultura e da sociedade mineira, que culminou numa política nacional para a diversificação agrícola, a modernização do campo e a formação do trabalhador nacional pela via da educação profissional agrícola.

Artigo recebido para publicação em 05/04/2013 Artigo aprovado para publicação em 27/04/2013 